TAO, Vol. 15, No. 2, 261-267, June 2004

NOTES AND CORRESPONDENCE

\title{
The Signature of Diversification of Source Processes in Controlling Atmospheric Mercury Levels in East Asia
}

\author{
Ki-Hyun Kim ${ }^{1, *}$ \\ (Manuscript received 3 October 2003, in final form 26 May 2004)
}

(Key words: Mercury, Anthropogenic, Emission, Source processes, Asia)

\section{INTRODUCTION}

The unique physicochemical properties of total gaseous mercury (TGM: primarily in its elemental form, $\mathrm{Hg}^{\mathrm{o}}$ ), characterized by strong stability, and long atmospheric residence time of approximately $1 \mathrm{yr}$, permit analysis of its temporal distribution patterns to be a potential indicator of air-quality change and associated source processes (Schroeder and Munthe 1998). In fact, large differences in concentration levels of $\mathrm{Hg}$ exist in many countries depending on their level of development and approaches to air quality management. In many Western countries, where significant efforts have been made in air quality control, the presence of moderately low $\mathrm{Hg}$ concentration values around $2.0 \mathrm{ng} \mathrm{m}^{-3}$ can readily be observed, even in locations adjacent to major metropolitan areas, Perch River area in New York, USA (Ames et al. 1998) or at certain source processes; for example, a coal-fired power station in Harwell, UK (Lee et al. 1998). This trend, however, contrasts sharply with what is observed in some Asian countries.

As many studies conducted on the Asian continent have focused on rapid urbanization, these differences in observed $\mathrm{Hg}$ concentration levels appear to be highly significant. For example, the presence of unusually high $\mathrm{Hg}$ concentrations, levels above $10 \mathrm{ng} \mathrm{m}^{-3}$ have been observed in a number of urban locations in China with relatively high frequency (Tan et al. 2000; Liu et al. 2002). In studies by Liu et al. 2002, the $\mathrm{Hg}$ values determined from eight different locations within Beijing City were highly variable depending on type of land-use and the temporal scale (seasonal and/or diurnal). Other Asian countries have also shared the presence of unusually high $\mathrm{Hg}$ data during different periods, such as Japan in the early 80s (Nakagawa 1995) and Korea in the late 80s (Kim and Kim 2000). Hence, the results of those

${ }^{1}$ Dept. of Earth and Environmental Sciences, Sejong University, Seoul, South Korea

* Corresponding author address.Dr. Ki-Hyun Kim, Dept. of Earth and Environmental Sciences, Sejong University, Goon Ja Dong, Seoul, SouthKorea; E-mail: kkim61@empal.com 
studies confirm unique aspects of mercury's geochemical behavior on the Asian continent, especially in terms of its relationship with anthropogenic processes. In light of complexities involved in the $\mathrm{Hg}$ distribution patterns across the Asian countries, the signature of different $\mathrm{Hg}$ source processes is discussed in terms of its relationship with spatial and/or temporal variability.

\section{RESULTS AND DISCUSSION}

In Table 1, the results of many studies conducted in a number of important locations in Asia are tabulated. As Liu et al. (2002) measured temporal and spatial variabilities of $\mathrm{Hg}$ from eight different sites in Beijing city, their results may be used as a good reference point to contrast the effects of different anthropogenic or natural source processes under varying environmental settings. In Fig. 1, the measurement data of Liu et al. are hence plotted to compare both seasonal and diurnal distribution patterns among their selected study sites within the city of Beijing. To account for the relative enhancement in summertime $\mathrm{Hg}$ levels observed in one urban downtown (Tiananmen Square: TS) and one suburban industrial station (Shijingshan: SS), Liu et al. pointed out surface temperature as the controlling mechanism of $\mathrm{Hg}$ levels; this is important because the evaporation of surface-bound $\mathrm{Hg}$ can be accelerated with increasing

Table 1a. A statistical summary of the mean concentrations of atmospheric $\mathrm{Hg}$ determined from a number of monitoring sites located in the East Asian countries.

\begin{tabular}{lcccccc}
\hline & Data Group & Industrial & Residential & Commercial & Rural & Remote \\
\hline \hline Korea & 1 & & $5.25^{1)^{*}}$ & $5.34^{2)}$ & & $4.47^{3)}$ \\
& 2 & $5.26^{4)}$ & $6.54^{5)}$ & & $7.03^{(1)}$ \\
& 3 & & & & $3.15^{7)}$ \\
Japan & 1 & $31.6^{8)}$ & $10.3^{9)}$ & & $5.73^{(0)}$ & $3.4^{(1)}$ \\
& 2 & & $16.5^{(2)}$ & & $42.4^{(3)}$ & \\
China** & 1 & $6.75^{(4)}$ & $16.7^{15)}$ & $10.5^{(5)}$ & $3.75^{(7)}$ & $3.35^{18)}$ \\
& 2 & & $8.47^{19)}$ & & &
\end{tabular}

* For detailed information of superscripts, refer to reference numbers provided in Table 1b.

** Except for reference 18, the mean values for each individual area in China were derived by summing up various mean values representing either daytime or nighttime for each season. 
Table 1b. Source information for the $\mathrm{Hg}$ data provided in Table 1a. All the reference nos. are identical to those given in Table 1a.

\begin{tabular}{llll} 
& & Number \\
Ref. No. Site $\quad$ City/Province $\quad$ Study period of data* & Author \\
\hline
\end{tabular}

$\begin{array}{cccccc}\text { A. Korea } & & & & \\ 1 & \text { residential } & \text { Kwa Chun } & 99 \sim 00 & 1992 & \text { Kim and Kim 2001b } \\ 2 & \text { Han Nam } & \text { Seoul City } & 99 \sim 00 & 2576 & \text { Kim and Kim 2001b } \\ 3 & 13 \text { Mountains } & \text { Nationwide, Korea } & 87 \sim 93 & 32 & \text { Kim and Kim 1996 } \\ 4 & \text { Yang Jae } & \text { Seoul City } & 99 \sim 00 & 11572 & \text { Kim and Kim 2001a } \\ 5 & \text { 3 Terminals } & \text { Seoul City } & \text { Mar. 98 } & 349 & \text { Kim and Kim 2001c } \\ 6 & 2 \text { Mountains } & \text { Korea } & 97 / 98 & 358 & \text { Kim and Kim 2001c } \\ 7 & \text { Hari } & \text { Kang Hwa Island } & 01 / 02 & 323 & \text { Kim ct al. 2003. }\end{array}$

\section{B. Japan}

$\begin{array}{cccccc}8 & \text { urban } & \text { Chiba and two others } & 91 \sim 96 / 94 & 40 & \text { Nakagawa and Hiromoto } 1997 \\ 9 & \text { urban areas } & \text { Chiba and three others } & 91 \sim 96 / 95 & 216 & \text { Nakagawa and Hiromoto } 1997 \\ 10 & \text { suburban } & \text { Kushiro and two others } & 91,94,95 & 31 & \text { Nakagawa and Hiromoto } 1997 \\ 11 & \text { Oceans } & \text { Japan sea/Pacific } & 91 & 4 & \text { Nakagawa and Hiromoto } 1997 \\ 12 & \text { rural city } & \text { Hayama and two others } & 91 \sim 96,95,96 & 64 & \text { Nakagawa and Hiromoto } 1997 \\ 13 & \text { Farmland } & \text { Tukui and two others } & 95 / 93 & 15 & \text { Nakagawa and Hiromoto } 1997\end{array}$

\section{China}

$\begin{array}{lccccc}14 & \text { Shijingshan } & \text { Beijing } & \text { Feb. \& Sept. } 98 & 12 \text { days } & \text { Liu ct al. } 2002 \\ 15 & \text { Xuanwu } & \text { Beijing } & \text { Jan. \& Sept. } 98 & 9 \text { days } & \text { Liu et al. } 2002 \\ 16 & \text { Tiananmen Sq. } & \text { Beijing } & \text { Feb. \& Sept. } 98 & 8 \text { days } & \text { Liu et al. } 2002 \\ 17 & \text { two rural sites } & \text { Beijing } & \text { Feb. \& Sept. } 98 & 9 \text { days } & \text { Liu et al. } 2002 \\ 18 & \text { Mountain sites } & \text { Giuizhou } & \text { Unreported } & 122 & \text { Tan et al. 2000 } \\ 19 & \text { residential } & \text { Beijing } & \text { Jan. \& Feb. } 98 & 15 \text { days } & \text { Liu et al. } 2002\end{array}$

* For data provided by Liu et al., all information is given as number of days. 


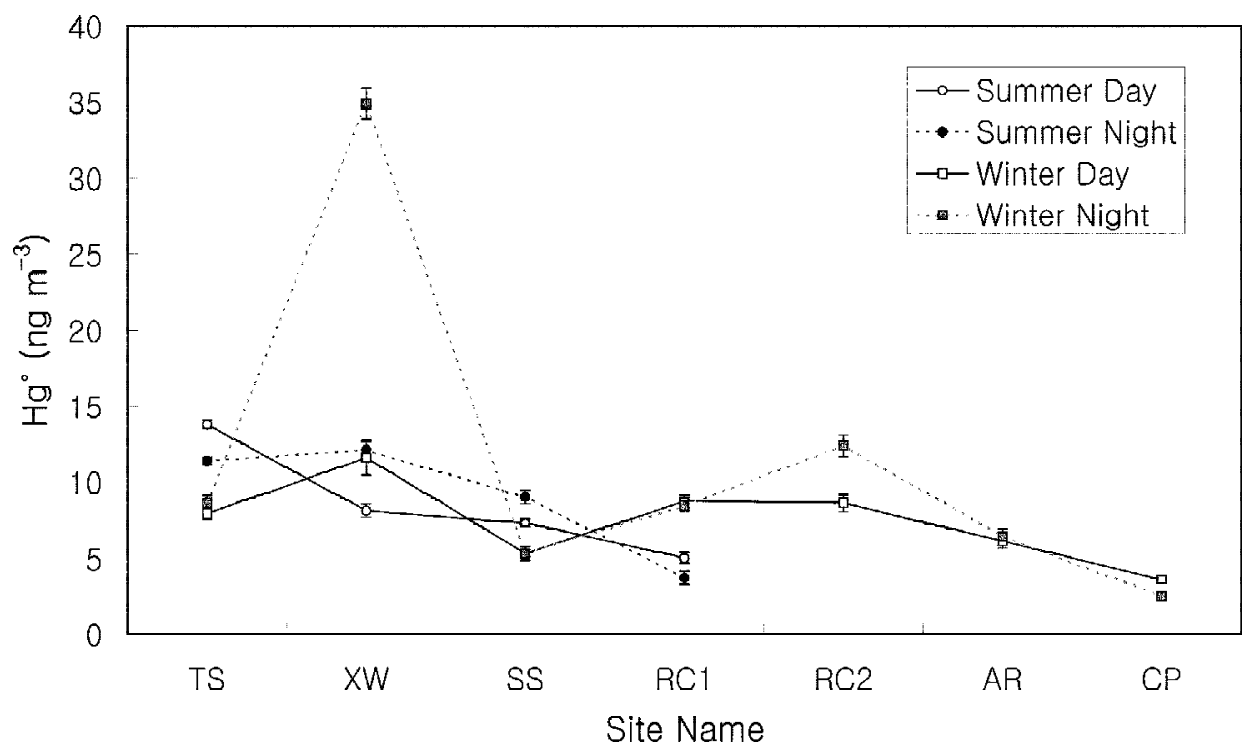

Fig. 1. Comparison of $\mathrm{Hg}$ concentrations determined from eight different locations of Beijing city, China (Liu et al. 2002). Results are plotted to compare changes across both seasonal (summer vs. winter) and diurnal scale (day vs. night). Error bars represent relative standard deviation. Actual names for each study site compared in this Figure are as follows: Tiananmen Square (TS), Xuanwu (XW), Shijingshan (SS), Research Center 1 (RC1), Research Center 2 (RC2), Atmospheric Research Institute (AR), Changping (CP), and Huairou County (HC).

temperature. However, based on the findings of enhanced $\mathrm{Hg}$ concentrations in the downtown area (TS) relative to the industrial area (SS), they suggested that anthropogenic processes were more prominent in the downtown area. To support their assertion, they quoted the results from a few urban areas in Asia wherein similar seasonal patterns were monitored: Seoul, Korea (Shon et al. 1993), and three urban sites in Tokyo/Sagami Bay, Japan (Nakagawa 1995). Temperature effect alone may have been important enough to explain the temporal patterns of $\mathrm{Hg}$ at those Beijing sites. This type of approach, however, is too simple to explain seasonal distribution patterns of $\mathrm{Hg}$ in urban areas, for there is a broad spectrum of anthropogenic processes.

It is in fact noted that a considerably different pattern exists simultaneously in a residential area of Beijing. Although these authors did not provide the full explanations for the different temporal patterns in the Xuanwu (XW) area, its results contrast sharply with those of the two other areas. The pattern at the XW site is characterized by the presence of an excessively high mean concentration recorded during a winter nighttime period $\left(34.9 \mathrm{ng} \mathrm{m}^{-3}\right)$; the site clearly exhibited relative enhancement during winter as apposed to summer, and nighttime as 
apposed to daytime levels. Although air pollution can be promoted under such meteorological conditions as winter and nighttime, the observed patterns in the residential area of Beijing are undoubtedly indicative of unusually strong anthropogenic source processes. It is striking to find that the patterns observed in the residential area of XW in Beijing are exceptionally compatible with what were seen in Seoul during the late 80s.

The previous studies of Kim and Kim (2000) offer some insights into the influences of anthropogenic processes on the distribution characteristics of TGM. They conducted a detailed analysis of the $\mathrm{Hg}$ data collected from several locations in Seoul during the late 80s, when the consumption of coal (e.g., anthracite) peaked. This research was continued further in the late 90 s by reinvestigating the $\mathrm{Hg}$ levels at some of the previous study sites in Seoul (Kim and Kim 2002). A series of comparative analyses made over a decade demonstrated tight relationships between the $\mathrm{Hg}$ levels and anthracite consumption patterns. It was thus concluded that the presence of exceptionally high $\mathrm{Hg}$ concentrations, those above $20 \mathrm{ng} \mathrm{m}^{-3}$ should be an indicator of such strong source processes. The temporal patterns of $\mathrm{Hg}$ distribution under the influence of those source processes were in fact systematic enough to distinguish between seasons and between concentration ranges, as those exceptional values were observed most intensively during winter with the highest seasonal mean. The patterns, however, were reversed completely after excluding those exceptional, upper-bound concentration data so that spring (and summer) recorded the highest seasonal mean. Unlike the results seen in those previous years, there are many indications that the present temporal patterns in Seoul (in the late 90s) have changed significantly due possibly to diversification of source processes (Kim and Kim 2002). It should be addressed that the present time $\mathrm{Hg}$, approximately $5 \mathrm{ng} \mathrm{m}^{-3}$ while being significantly lower than those levels observed in the late $80 \mathrm{~s}\left(>10 \mathrm{ng} \mathrm{m}^{-3}\right)$, exhibits indistinguishable differences in its seasonal mean values. Hence, one may expect that the effects of source processes, even anthropogenic ones, can vary through time.

It is well known that chlor-alkali plants belonged to the predominant anthropogenic source of $\mathrm{Hg}$ emissions in many industrial countries prior to 1970s (Schroeder and Munthe 1998). However, relative dominance of anthropogenic sources changed very rapidly with the implementation of various regulating controls. Along with changes in fuel consumption patterns, various man-made activities are pointed out to be important sources of $\mathrm{Hg}$ in urban air. For instance, it was reported that the gaseous $\mathrm{Hg}^{\mathrm{o}}$ emissions from municipal solid waste (MSW) incinerators were one of the important sources of $\mathrm{Hg}$ (Sakata and Marumoto 2002); they found that such a $\mathrm{Hg}$ source could account for the dominant fraction of particulate $\mathrm{Hg}$ levels occurring in the Tokyo metropolitan area. The significance of a series of metal handling processes (such as refining, smelting, etc) has also been reported (Nriagu and Pacyna 1988).

Considering that the urbanization and industrialization of China are progressing rapidly along with notable increases in coal consumption (Xiao et al. 1998), the simple explanation of Liu et al. (such as the temperature effect) may not be sufficient in explaining the observed differences in urban areas of various characteristics. A line of evidence including an exceptionally wide range of the mean concentrations such as from 2.5 (winter nighttime in a rural area) to $34.9 \mathrm{ng} \mathrm{m}^{-3}$ (winter nighttime in a residential area) and diverse features of temporal variability in the city of Beijing suggests the possibility that the source processes of $\mathrm{Hg}$ in the urban areas of Asia are extremely diverse. 
Acknowledgements This research was supported by a Korean Science and Engineering Foundation (KOSEF) Grant (R02-2002-000-00055-0).

\section{REFERENCES}

Ames, M., G. Gullu, and I. Olmez, 1998: Atmospheric mercury in the vapor phase, and in fine and coarse particulate matter at Perch river, New York. Atmos. Environ., 32, 865-872.

Kim, K.-H., and M.-Y. Kim, 1996: Preliminary measurements of atmospheric mercury in mountainous regions of Korea. J. Environ. Sci. Health, A31, 2023-2032.

Kim, K. -H., and M. -Y. Kim, 2000: The effects of anthropogenic sources on temporal distribution characteristics of total gaseous mercury in Korea. Atmos. Environ., 34, 33373347.

Kim, K.-H., and M.-Y. Kim, 2001a: The temporal distribution characteristics of total gaseous mercury from an urban monitoring site in Seoul during 1999 to 2000. Atmos. Environ., 35, 4253-4263.

Kim, K.-H., and M.-Y. Kim, 2001b: Distribution characteristics of atmospheric mercury from two monitoring stations: inside and outside of Seoul metropolitan city, Korea. J. Korean Earth Sci. Soc., 22, 223-236.

Kim, M.-Y., and K.-H. Kim, 2001c: Regional distribution characteristics of total gaseous mercury in air - measurements from urban and mountainous sites in Korea.J. Korean Soc. Atmos. Environ., 17, 39-50.

Kim, K. -H., and M. -Y. Kim, 2002: A decadal shift in total gaseous mercury concentration levels in Seoul, Korea: changes between the late 1980s and the late 1990s. Atmos. Environ., 36, 663-675.

Kim, K. -H., M. Y. Kim, J. Kim, and G. Lee, 2003: Effects of changes in environmental conditions on atmospheric mercury exchange: Comparative analysis from a rice paddy field during the two spring periods of 2001 and 2002.J. Geophys. Res., 108, 4607, doi: 10.1029/2003JD003375.

Lee, D. S., G. J. Dollard, and S. Pepler, 1998: Gas-phase mercury in the atmosphere of the United Kingdom. Atmos. Environ., 32, 855-864.

Liu, S., F. Nadim, C. Perkins, R. J. Carley, G. E. Hoag, Y. Lin, and L. Chen, 2002: Atmospheric mercury monitoring survey in Beijing, China. Chemosphere, 48, 97-107.

Nakagawa, R., 1995: Studies on the levels in atmospheric concentrations of mercury in Japan. Chemosphere, 31, 2669-2676.

Nakagawa, R., and M. Hiromoto, 1997: Geographical distribution and background levels of total mercury in air in Japan and neighbouring countries. Chemosphere, 34, 801-806.

Nriagu, J. O., and J. M. Pacyna, 1988: Quantitative assessment of worldwide contamination of air, water and soils by trace metals. Nature, 333, 134-139.

Sakata, M., and K. Marumoto, 2002: Formation of atmospheric particulate mercury in the Tokyo metropolitan area. Atmos. Environ., 36, 239-246. 
Schroeder, W. H., and J. Munthe, 1998: Atmospheric mercury-an overview. Atmos. Environ., 32, 809-822.

Shon, D. H., W. T. Jung, and D. Kim, 1993: Distribution of total mercury in the ambient atmosphere of Seoul and its diurnal, monthly and altitudinal variations.Jpn. J. Toxicol. Environ. Health, 39, 582-588.

Tan, H., J. L. He, L. Liang, S. Lazoff, J. Sommer, Z. F. Xiao, and O. Lindqvist, 2000: Atmospheric mercury deposition in Guizhou, China. Sci. Total Environ., 259, 223-230.

Xiao, Z. F., J. Sommar, O. Lindqvist, H. Tan, and J. L. He, 1998: Atmospheric mercury deposition on Fanjing Mountain Nature Reserve, Guizhou, China. Chemosphere, 36, 2191-2200. 